\title{
Study of Urological Injuries in Obstetric and Gynaecological Procedures
}

\author{
Authors \\ *Dr Purna Chandra Mahapatra ${ }^{1}$, Dr Sujata Swain², Dr Rabi Narayan Satpathy ${ }^{3}$, \\ Dr Surbhi Snehi Indubhushan ${ }^{4}$, Dr Jenny Gonmei ${ }^{5}$ \\ ${ }^{1}$ Professor, Dept. of Obs \& Gyn, SCBMCH, Cuttack, Odisha, India \\ ${ }^{2}$ Asso. Professor, Dept. of Obs \& Gyn, SCBMCH, Cuttack, Odisha, India \\ ${ }^{3}$ Asst. Professor, Dept. of Obs \& Gyn, SCBMCH, Cuttack, Odisha, India \\ ${ }^{4,5}$ PG Student,Dept. of Obs \& Gyn, SCBMCH, Cuttack, Odisha, India \\ Corresponding Author
}

\section{Dr Surbhi Snehi Indubhushan}

PG Student,Dept. of Obs \& Gyn, SCBMCH, Cuttack, Odisha, India

Email: surbhisnehi1987@gmail.com,8076162184

\begin{abstract}
Aim: To study the urological injuries sustained by women during the various obstetric and gynaecological procedures with respect to their incidence, frequency, predisposing factors, location, time of recognition, prevention, associated morbities, their effect on the lifestyle of women and mangement and follow-up.

Methods: This is an observational tertiary care hospital based study. All the women who underwent obstetric and gynaecological procedures including caesarean section, hysterectomies, laparoscopic procedures, instrumental deliveries and radical surgeries were observed. Amongst these, the women who sustained urological injuries during these procedures were studied with respect to incidence, predisposing factor, location, time of recognition, obstetric status, procedure commonly associated, age group and management. These women were followed up over a period of 3 months to detect any sequelae.

Results: Incidence of urological injury in our setup was $0.28 \%$.Incidence during obstetric procedures was $0.28 \%$ whereas that during gynaecological procedures was $0.32 \%$. No cases of urological injury were encountered during laparoscopic procedures. Injury to the urinary bladder, ureter and urethra constituted $96.8 \%, 3.12 \%$ and $3.12 \%$ respectively. Thus, urinary bladder is the most frequently injured urological organ. The most common predisposing factors were obstructed labor and previous cesarean section. Cesarean section was the most frequently performed surgery. These injuries were more frequently found in second gravida patients. During gynecological procedures, a history of prior caesarean sections was found to be associated with difficult dissection. The urological injuries were found maximum in the age group of 20-25 years. The mortality rate in our study is $3.12 \%$.
\end{abstract}

Keywords: Urological injuries, bladder, ureter, caesarean section.

\section{INTRODUCTION}

Injury to urinary tract in medical practice was first described in $1030 \mathrm{AD}$ in the opus called 'AlKanoun'. It was earlier observed by Derry in the mummy of Henhenit who lived in the court of King Mentuhotep II in 2050 BC. Urological injuries are an important concern of obstetricians and gynaecologists especially during 
hysterectomies and caeserian sections. These injuries are rare, but feared, complications. These injuries occur mostly due to difficult surgeries and/or associated with active infections, endometriosis, enlarged uterus, previous pelvic surgery, pelvic adhesions, ovarian neoplasms, distorted pelvic anatomy, pelvic fibroid and broad ligament fibroid. Laparoscopic procedures carry a higher risk of ureteric injuries and similar risk of urinary bladder injuries. The morbidities arising from such injuries include increased blood loss, longer hospital stay, more secondary invasive interventions, potential loss of renal functions and deterioration of woman's quality of life. Most of these injuries are associated with attempts to secure hemostasis and tissue. It has been estimated that $0.5-2.5 \%$ of all obstetric and gynaecological procedures have been reported to cause such injuries. The main reason for these injuries is the close proximity of the organs of female reproductive system and the urological system. Prevention is the best option for maintaining urinary tract integrity. Excellent knowledge of the pelvic anatomy and procedure, as well aspatience, skilled assistance, lighting, adequate exposure and attention to detail are all of paramount importance. Bladder injury is less likely if the bladder is emptied before the procedure. Intraoperative recognition and repair under the same anaesthesia improves outcome. A high index of suspicion serves both the patient and the surgeon well. Recent data suggest that a case can be made for universal cystoscopy, particularly after hysterectomy, anterior repair, and other high risk procedures. Hence it is important to recognise these injuries in time, assess them and rectify them to improve the quality of life of the patient.

\section{SUBJECTS AND METHODS}

This is an observational hospital based study conducted in the Department of Obstetrics \& Gynaecology, S.C.B. Medical College \& Hospital, Cuttack from September,2013 to September, 2015. All women who sustained injuries to any organ of the urinary system due to any obstetric or gynaecological procedures were followed up and informed written consent was taken from patients who were eligible for the study. Patients who sustained urological injuries during obstetric \& gynaecological procedures at other centres and came to our Department for management of complications were not included for this study.

Method used for diagnosis of urological injuriesThe presence of urine in operative field served as a major clue to suspicion of bladder injury. Large cystostomies were prominent by itself while small perforation were detected by filling the bladder with normal saline or with normal saline stained with dye. Ureteric injuries were difficult to diagnose intraoperatively. However, a high degree of suspicion in difficult cases of scarring, carcinoma cervix, large pelvic masses and hemorrhage helped in confirmaton of ureteric integrity by giving injection of frusemide and looking for urinary leakage, ureteric dilatation and peristalsis. In our study, ureteric injury was identified by appearance of urine in the operative field and identification of peristalsis of the ureter.

\section{OBSERVATIONS}

Table 1: Relationship between distribution of injuries and the obstetric status of the patients

\begin{tabular}{|l|c|}
\hline Obstetric Status & No. of cases \\
\hline Primigravida & 11 \\
\hline Second Gravida & 12 \\
\hline Third gravida & 6 \\
\hline
\end{tabular}

Table 2: Relationship between the injuries and the type of procedure

\begin{tabular}{|l|c|c|c|}
\hline & $\begin{array}{c}\text { Total no. } \\
\text { of cases }\end{array}$ & $\begin{array}{c}\text { No. of cases } \\
\text { of injury }\end{array}$ & Incidence \\
\hline Obstetric procedure & 9802 & 28 & $0.28 \%$ \\
\hline Gynaecological procedure & 1250 & 4 & $0.32 \%$ \\
\hline
\end{tabular}

Table 3: Distribution of injuries based on predisposing factors is as follows.

\begin{tabular}{|l|c|c|}
\hline Predisposing Factor & No. of cases & Incidence \\
\hline Obstructed labor & 11 & $34.37 \%$ \\
\hline Previous CS & 11 & $34.37 \%$ \\
\hline Prev. CS with placenta previa & 3 & $9.3 \%$ \\
\hline Rupture uterus & 2 & $6.2 \%$ \\
\hline Uterovaginal Prolapse & 2 & $6.2 \%$ \\
\hline Endometriosis & 1 & $3.1 \%$ \\
\hline Others & 2 & $6.2 \%$ \\
\hline
\end{tabular}


Table 4: Distribution of injuries based on operation

\begin{tabular}{|l|c|c|c|}
\hline Procedure & $\begin{array}{c}\text { Total no. } \\
\text { of cases }\end{array}$ & $\begin{array}{c}\text { No. of patients } \\
\text { with injury }\end{array}$ & Percentage \\
\hline LSCS & 9124 & 25 & $0.27 \%$ \\
\hline VH & 707 & 2 & $0.28 \%$ \\
\hline TAH & 516 & 2 & $0.38 \%$ \\
\hline TLH & 3 & 0 & 0 \\
\hline LAVH & 19 & 0 & 0 \\
\hline Rupture uterus repair & 94 & 2 & $2.12 \%$ \\
\hline Radical surgeries & 14 & 0 & 0 \\
\hline Others & 649 & 2 & $0.30 \%$ \\
\hline
\end{tabular}

Total no. of patients who suffered urological injuries was 32. Total no. of injuries were 33 as one patient had injuries to two organs.

Table 5: Location of the injuries is as follows.

\begin{tabular}{|l|c|c|}
\hline Location & No. of patients & Percentage \\
\hline Ureter & 1 & $3.12 \%$ \\
\hline Urinary Bladder & 31 & $96.8 \%$ \\
\hline Urethra & 1 & $3.12 \%$ \\
\hline
\end{tabular}

Table 6: Distribution of injuries in various age groups is as follows.

\begin{tabular}{|l|c|}
\hline Age Group & No. of cases \\
\hline 20-25 years & 13 \\
\hline 26-30 years & 10 \\
\hline 31-35 years & 6 \\
\hline >35 years & 3 \\
\hline
\end{tabular}

Time of recognition of the injuries- At our centre, all the injuries were recognised intraoperatively during the same procedure.

\section{MANAGEMENT}

\section{Management of bladder injury}

- The bladder injuries were repaired with Polyglactin 2-0 in layers by the urologist.

- Foley's per urethral catheter was kept insitu for 3 weeks in these cases. 7 of these patients were also given suprapubic catheter for 10-12 days with daily irrigation.

- Serum urea, Serum creatinine and CBC were investigated on alternate days till day 8 and then at weeks 3, 6 and at 3 months. After removal of per urethral catheter an abdominal scan was done for each of these patients to check for any urine leak.
- Also PVRU volume were measured in these patients after removal of the catheter.

- In all these patients, no urine leak was detected and PVRU was within normal limit.

\section{Management of ureteric injury}

- In one patient of left ureteric injury, a DJ stent was given and the ureter was repaired with Polyglactin 4-0 by the urologist.

- Foley's catheter was kept in situ for 6 weeks. The DJ stent was removed at 3 months by the urologist.

- Serum urea, Seum creatinine and CBC were done on alternate days postoperatively till day 8 and then at weeks 3 and 6 and then at 3 months.

- The values in all the patients were found to be within normal limits.

- Abdominal scan in the patient at 6 weeks and 3 months showed no urine leak and PVRU was found to be within normal limit.

- Kidneys were found to be normal on abdominal scan.

\section{Management of urethral injury}

- As it was a minor stretch injury, no treatment was required.

- On follow up, patient did not have any signs and symptoms.

\section{RESULT}

Out of the 32 patients who sustained urological injuries during obstetrical and gynaecological procedures, one patient did not survive. The patient succumbed on post-operative day 5 . Indication for surgery in this patient was previous CS with central placenta previa with GTD invading the bladder mucosa. Cause of death was septicemia. Predisposing factors for urological (bladder) were dense pelvic adhesions, placenta previa with prior caeserean section. Thus the mortality rate in our study was found to be $3.12 \%$ of all such patients. 
Table 8: Incidence of urological injuries

\begin{tabular}{|l|c|c|}
\hline $\begin{array}{l}\text { Total no. of } \\
\text { operations }\end{array}$ & $\begin{array}{c}\text { No. of cases } \\
\text { with injuries }\end{array}$ & Incidence \\
\hline 11126 & 32 & $0.28 \%$ \\
\hline
\end{tabular}

The incidence during obstetric procedures was $0.28 \%$ and that during gynecological procedures was $0.31 \%$.

The incidence of injuries in various other studies are as follows

\section{Table 9}

\begin{tabular}{|c|c|c|}
\hline Year & Author & Incidence \\
\hline 1991 & Raut V et al $^{5}$ & $1.26 \%$ \\
\hline 1995 & ${\text { M Rifat et } \mathrm{al}^{7}}^{7}$ & $0.18 \%$ \\
\hline 2002 & ${\text { Carley et } \mathrm{al}^{9}}^{9}$ & 0.3 to $5.13 \%$ \\
\hline 2004 & ${\text { Yossepwich et } \mathrm{al}^{10}}^{13}$ & $0.27 \%$ \\
\hline 2012 & Mesfer Al Shahrani $^{13}$ & $0.22 \%$ \\
\hline 2012 & Joong Shik Lee et al $^{14}$ & $0.20 \%$ \\
\hline 2015 & Our study & $0.28 \%$ \\
\hline
\end{tabular}

\section{DISCUSSION}

The ureter is closely related to the female reproductive system. As ureter lies anterior to the internal iliac artery and immediately behind ovary, it forms the posterior boundary of the ovarian fossa. It descends down till the ischial spine. Then it courses anteromedially towards the urinary bladder. In its anteromedial part, ureter is related to the uterine artery, cervix and vaginal fornices. Ureter lies in endopelvic fascia in inferomedial part of the broad ligament of uterus where it may be damaged. In the broad ligament, uterine artery is anterosuperior to ureter by $2.5 \mathrm{~cm}$ and then crosses the ureter to ascend along the lateral side of the uterus. Ureter runs forwards slightly above the lateral fornix of the vagina and is $2 \mathrm{~cm}$ lateral to supravaginal part of cervix. It then turns medially towards the urinary bladder and is apposed to the vagina. Left ureter is often more close to the vagina, as uterus is slightly on the right side and vagina is on the left side of the median plane. One has to be careful of ureter especially during ligation of the uterine artery. Ureter exhibits peristaltic movement. Thus, there is a close anatomical association between the urological and reproductive systems in human females. Injury to the urological tract is quite possible during obstetric and gynaecological procedures due to this. Skills on part of the surgeon is essential to avoid such injuries. Also timely intervention in the event of such injury can avoid long term adverse sequelae.

\section{Changing trends in urological injuries}

With the advent of newer techniques and intruments, as the surgeries have become more convenient for the surgeons, the etiology of urological injuries have changed too. Earlier it was mostly due to securing the tissue with clamps or to attain hemostasis. In today's world, electrosurgeries are contributing to such injuries too. Electric sealers and cutters not only cause injuries due to clamping action but also due to their cauterising action. These cause thermal injuries to the urinary tract. Also interventional radiology79 has come up as a source of injuries to the urological organs.

\section{Medicolegal aspects}

From a medicolegal point of view, it is wise to include a description of the identification of the bladder and ureters in the operation record. If the urological injury is sustained during dissection of adhesion, it may be defensible. If the urological organs are in abnormal position- for example, bladder is high up over the uterus during LSCSthen injury is more likely to occur. In such cases, the damage caused to the bladeer would not be negligent. If the injury is not recognised intraoperatively, it may invite penalty.

Hence, to avoid these medicolegal problems it is wise to discuss about these urological injuries during counselling. While preparing the patient for any obstetrical and gynaecological surgery, the predisposing factors must be recognised and due care must be taken intraoperatively. Also the surgeon must keep a written evidence of it.

\section{COMPLICATIONS}

$>$ Stricture

$>$ Excessive drainage

$>$ Stent and nephrostomy related problems

$>$ Urinary tract infection 
Ureteric obstruction or reflux

$>$ Hematoma

$>$ Wound infection

$>$ Fistula.

In our study, the only complication seen was septicemia leading to death of one patient.

\section{CONCLUSION}

An observational retrospective study of 32 cases of urological injuries in obstetrical and gynaecological surgeries was conducted. Incidence of urological injury in our setup was found to be $0.28 \%$. The incidence during obstetric procedures was $0.28 \%$ whereas that during gynaecological procedures was $0.32 \%$. There were no cases of urological injury encountered during laparoscopic procedures. The reason for this is that our laparoscopy unit is quite new and that laparoscopic surgeries are performed by expert surgeons in this field.

Injury to the urinary bladder, ureter and urethra constituted $96.8 \%, 3.12 \%$ and $3.12 \%$ respectively. Thus, urinary bladder is the most frequently injured urological organ. The most common predisposing factors were found to be obstructed labor and previous cesarean section. Cesarean section was the most frquently performed surgery. It contributed to maximum number of cases of urological injury. Highest incidence was associated with rupture uterus $(2.1 \%)$. These injuries were also more frequently found in second gravid patients. Also during gynecological procedures, a history of prior caesarean sections was found to be associated with difficult dissection, thus making the urinary tract prone to iatrogenic injury. The urological injuries were found maximum in the age group of 20-25 years.

All the injuries were diagnosed intraoperatively and meticulously repaired primarily in our hospital. The method used for diagnosis of ureteric injury was evidence of urine in the operative field and looking for peristalsis. For diagnosing bladder injury, retrograde infiltration with stained saline was used. The morbidities in these patients included a longer hospital stay, indwelling Foley's catheter for longer duration and blood and urine investigations for longer duration and follow up for longer period of time. The mortality rate in our study has been found to be $3.12 \%$. Associated comorbidities were placenta previa and GTD invading bladder mucosa. The cause of death was septicemia.

Urological injuries though uncommon are an important contributor to morbidity in Obstetrics and Gynaecology. Obstetric and gynaecological injuries contribute to almost $50 \%$ of urological injuries64. Knowledge of pelvic anatomy and its alteration due to any reason, careful dissection and patience in difficult cases and the skills of the surgeon are the key factors to anticipate and prevent injuries. To reduce postoperative morbidities, intraoperative recognition of injury and primary repair is essential.

\section{REFERENCES}

1. Raghavaiah NV, Devi AI. Bladder Injury Associated With Rupture of the Uterus. Obstet Gynecol. 1975 Nov; 46(5): 573-6.

2. Thorkild F. Nielsen \& Klas-Henry Hökegård, Cesarean Section and Intraoperative Surgical Complications. Acta Obstetricia et gynecologica Scandinavica. 1984, 63(2): 103-108.

3. Badenoch DF, Tiptaft RC, Thaker DR, Flower CG, Blandy JP. Early repair of accidental injury to the ureter or bladder following gynaecologic surgery. Br J Urol. 1987 Jun; 59(6):516-18.

4. Chen D. Urinary complications following Radical Hysterectomy for 621 patients with cancer of uterine cervix: Chung Hua Chung Liu-Tsa-Chih ( Eng. Abst) 1989; 11(1): 67.

5. Raut V, Shrivastava A, Nandanwar S, Bhattacharya M.Urological injuries during Obstetric and Gynaecological procedures. J Postgrad Med .1991; 37: 21-3.

6. Neuman M, Eidelman A, Langer R, Golan A, Bukovsky I, Caspi E. Iatrogenic injuries to the ureter during gynecologic and 
obstetric operations. Surg Gynecol Obstet. 1991;173:268-272.

7. Mamoona Rifat, Lubna Hassan. Urological injuries during gynaecological surgery- a retrospective study. Pakistan JPMI- 1995; 9(1): 62-66.

8. Onuora VC, al Ariyan R, Koko AH, Abdelwahab AS, Al Jawini N.Major injuries to the urinary tract in association with childbirth. East Afr Meed J. 1997 Aug; 74(8): 523-6.

9. Carley ME, McIntire D, Carley JM, Schaffer J. Incidence, risk factors and morbidity of unintended bladder or ureter injury during hysterectomy. Int Urological J Pelvic floor Dysfunction 2002; 13(1):1821.

10. Yossepwitch O, Baniel J, Livne PM, Urological injuries during caesarean section: intraoperative diagnosis and management. J Urol, 2004 Jul; 172(1): 196-9.

11. Swati Jha, Aravinthan (Arri) Coomaraswamy, Kiong Kong Chan. Ureteric injury in Obstetric and gynecological surgery; J RCOG 2004; 6: 203- 208.

12. Purandare $\mathrm{CN}$, Urological injuries in Gynaecology. J Obstet Gynecol India. 2007; 57: 204-4.

13. Mesfer Al- Shahrani. Bladder injury during caesarean section: a case control study of 10 years. Bahrain Medical Bulletin, Vol. 34, No. 3, September 2012.

14. Joong Shik Lee, Jin Ho Choe, Hyo Serk Lee and $\mathrm{Ju}$ Tae Seo, Urological complications following Obstetric and Gynecologic Surgery. Korean J Urol. 2012 Nov; 53(11): 795-799. 